\title{
Hepato-protective influence of quercetin and ellagic acid on thioacetamide-induced hepatotoxicity in rats
}

\begin{tabular}{|r|l|}
\hline Journal: & Canadian Journal of Physiology and Pharmacology \\
\hline Manuscript ID & cjpp-2017-0651.R1 \\
\hline Manuscript Type: & Article \\
\hline Date Submitted by the Author: & 16-Nov-2017 \\
\hline Complete List of Authors: & $\begin{array}{l}\text { Afifi, Nehal; Cairo University, pharmacology } \\
\text { Ibrahim, Marwa; Cairo University } \\
\text { Galal, Mona; Cairo Universty, }\end{array}$ \\
\hline Keyword: & Quercetin, ellagic acid, Hepatotoxicity, Antioxidant, anti-fibrotic \\
\hline $\begin{array}{r}\text { Is the invited manuscript for } \\
\text { consideration in a Special } \\
\text { Issue?: }\end{array}$ & N/A \\
\hline
\end{tabular}




\title{
Title page
}

\section{Hepato-protective influence of quercetin and ellagic acid on thioacetamide- induced hepatotoxicity in rats}

\author{
Afifi, N. A ${ }^{\text {a }}$; Marwa A. Ibrahim ${ }^{\text {b }}$, Mona K. Galal ${ }^{\text {b* }}$ \\ ${ }^{a}$ Pharmacology Department, Faculty of Veterinary Medicine, Cairo University, Giza, \\ Egypt, 12211. \\ ${ }^{b}$ Department of Biochemistry and Chemistry of Nutrition, Faculty of Veterinary \\ Medicine, Cairo University, Giza, Egypt. \\ Prof. Dr. Nehal Aly Afifi Email drnehal_affifi@hotmail.com \\ Dr. Marwa Ibrahim Email_marwa199@gmail.com \\ Dr. Mona Galal Email monagalal12@gmail.com
}




\section{Abstract}

Despite all the studies performed up to now, therapy choices for liver injuries are very few. Therefore, the search for a new treatment that could safely and effectively block or reverse liver injuries remains a challenge. The Quercetin $(\mathrm{QR})$ and ellagic acid (EA) had a potent antioxidant and anti-inflammatory activities. The current study aimed at evaluating the potential hepatoprotective influence of QR and EA against thioacetamide (TAA)-induced liver toxicity in rats and the underlying mechanism using silymarin as a reference drug. Fifty mature male rats were orally daily treated with EA and QR in separate groups for 45 consecutive days, and then were injected with TAA twice with 24 hours interval in the last two days of the experiment. Administration of TAA resulted in marked elevation of liver indices, alteration in oxidative stress parameters and significant elevation in expression level of fibrosis related genes (MMP9 and MMP2). Administration of QR and EA significantly attenuated the hepatic toxicity through reduction of liver biomarkers, improving the redox status of the tissue as well as hampered the expression level of fibrosis related genes. In conclusion, QR and EA were proved to attenuate the hepatotoxicity through its antioxidant, metal chelating capacity and anti-inflammatory effects.

Key words: Quercetin; ellagic acid; Hepatotoxicity; Antioxidant; anti-fibrotic. 


\section{Introduction}

Liver fibrosis remain one of the main causes of morbidity and mortality worldwide (Sanchez-Valle et al. 2012). Nowadays, the use of antifibrotic drugs is increasing in order to improve liver regeneration. One of the main drugs of antifibrotic activity is pirfenidone it had main role in inhibition of NF-KB protein activation, down-regulation of TGF- $\beta 1$, TIMP-1, MMP-2 mRNA and collagen deposition (Salas-Villalobos et al. 2017). Although considerable advances have been made for liver diseases treatment including pharmacotherapy, surgery, and liver transplantation, none of these options is optimum and has their considerable complications (Muriel and Rivera-Espinoza 2008). Clearly, there is a critical need for exploring novel and alternative approaches for either protection and or treatment of liver disease. thioacetamide (TAA), a hepatotoxic agent, could produce hepatic necrosis, as well as fibrosis or cirrhosis in chronic administration (Lin et al. 2017 ). Hepatic cirrhosis development involves oxidative stress, hepatic inflammation, stellate cells activation and fibrosis (Hernández-Ortega et al. 2012). One of the main mechanisms involved in the development and pathogenesis of liver diseases is oxidative stress (Cichoż-Lach and Michalak 2014) .Subsequently, the use of natural antioxidants rather than synthetic drugs has risen as an alternative strategy to attenuate or prevent liver injury (Bursal et al. 2013). Ellagic acid (EA) is a polyphenolic compound derived from plants found in a wide variety of nuts and fruits (Soong and Barlow 2004). It has been reported to possess various pharmacological actions including antioxidant, antimutagenic, anti-apoptotic, anticarcinogenic, antibacterial, antiviral, anti-allergic, antiinflammatory, antidiabetic, anti-epileptic, antidepressant, neuroprotective, pneumoprotective, nephroprotective, cardioprotective and hepatoprotective 
activities (García-Niño and Zazueta 2015). Quercetin (QR), a naturally occurring bioflavonoid, is widely distributed in fruits, vegetables and cereals. It possesses powerful antioxidant and cytoprotective effects (Choi et al. 2003) and various pharmacological actions including anti-inflammatory, hepatoprotective, renoprotective and neuroprotective effects (Cai et al. 2013). Growing experimental data have illustrated that $\mathrm{QR}$ and EA have the ability to offer hepatoprotection and inhibit liver fibrosis. However, the exact molecular mechanisms still remain unclear (Buniatian 2003; Tieppo et al. 2009; HernándezOrtega et al. 2012). The aim of the present work is to investigate the possible hepatoprotective mechanisms of EA and QR against TAA-induced hepatotoxicity in rats and elucidate the possible underlying mechanisms.

\section{Material and methods}

\subsection{Drugs}

Ellagic acid ( $\geq 95 \%$ (HPLC) analytical standard grade, powder). Quercetin ( $\geq 95 \%$ (HPLC) analytical standard grade, solid). They were purchased from Sigma- Aldrich Chemical Company (USA). Silymarin was purchased from MEPACO, Egypt as a fine powder. All drugs suspensions were prepared by dissolving in distilled water and 1\% tween 80 . The drugs suspensions were prepared fresh daily and stored at cool and dry place in dark before use.

\subsection{Experimental Animals}

Fifty adult male rats weighting 200-220 g were obtained from Pharmacology Department, Faculty of Veterinary Medicine, Cairo University were used in the present study. All animals were subjected to two weeks of acclimatization. The animals were housed in separate well-ventilated cages, under standard conditions, with free access to standard diet and water according to guide for the Care and Use of 
Laboratory Animals (Guide for the Care and Use of Laboratory Animals (2011). The local Committee for Faculty of Veterinary Medicine, Cairo University approved the design of the experiments and the protocol conforms to the guidelines of the National Institutes of Health.

\subsection{Experimental protocol}

For 45 days the rats were divided into five equal groups. Group I: (control group) received distilled water containing 1\% Tween 80 p.o, Group II: received TAA (300 $\mathrm{mg} / \mathrm{kg}$, i.p.) twice with 24 hours interval in the last two days of the experiment (Yogalakshmi et al., 2010). Group III: received silymarin (Standard hepatoprotective reference drug) (50 mg/kg, p.o.) (Pradhan and Girish 2006) for 45 consecutive days and TAA (300 mg/kg, i.p.) twice with 24 hours interval in the last two days of the experiment. Group IV: received QR (100 mg/kg, p.o.) (El-Nekeety et al. 2014) for 45 consecutive days and TAA (300 mg/kg, i.p.) twice with 24 hours interval in the last two days of the experiment. Group V: received EA $(100 \mathrm{mg} / \mathrm{kg}$, p.o.) (El-Shitany et al. 2014) for 45 consecutive days and TAA (300 mg/kg, i.p.) twice with 24 hours interval in the last two days of the experiment.

\subsection{Sampling}

At the end of the experimental period, blood samples were collected under light ether anesthesia and collected in clean test tubes, allowed to clot, then centrifuged for 10 minutes at 3000 r.p.m. Serum was separated and stored at $-20{ }^{\circ} \mathrm{C}$ to be used for determination of liver function tests and total antioxidant capacity. After collection of blood samples, rats were sacrificed by cervical dislocation and their livers were immediately removed for subsequent analysis.

\section{4. Liver function tests}


The liver function was evaluated based on measurement of the serum levels of alanine aminotransferase (ALT), aspartate aminotransferase (AST) and alkaline phosphatase (ALP) according to the instructions provided by the manufacturer of the Kits.

\subsection{Estimation of lipid peroxidation and antioxidants parameters in liver tissue}

Specimens from liver tissue was weighted and homogenized in cold phosphate buffered saline ( $\mathrm{pH}$ 7.4) using Teflon homogenizer. The homogenates were centrifuged at $14,000 \times \mathrm{g}$ for $15 \mathrm{~min}$ at $4{ }^{\circ} \mathrm{C}$. The supernatant was used to measure the glutathione peroxidase enzyme (GPX) activity (Deng et al. 2000), MDA (Ohkawa et al. 1979) and estimation of protein content (Bradford 1976). The serum sample was also used to measure total antioxidant capacity (TAC) according to the instructions provided by the manufacturer of the Kit.

\subsection{Quantitative real-time PCR (qRT-PCR) for matrix metalloproteinase 9 (MMP9) and (MMP2)}

Approximately $100 \mathrm{mg}$ of liver tissue was used for total RNA extraction using Qiagen Rneasy Mini Kit following the manufacturer's protocol. The RNA yields and purity were determined using Spectrophotometer (Thermo Scientific, USA). Total RNA were treated with DNase I for $20 \mathrm{~min}$ at $37^{\circ} \mathrm{C}$. The cDNA synthesis was carried out using reverse transcriptase (Invitrogen) and oligo-dT following the manufacturer protocol. After initial heat denaturation of $1 \mu \mathrm{g}$ of total $\mathrm{RNA}\left(65^{\circ} \mathrm{C}\right.$ for $\left.5 \mathrm{~min}\right)$, the reactions $(20 \mu \mathrm{l})$ were incubated for $60 \mathrm{~min}$ at $44^{\circ} \mathrm{C}$. cDNA was added to a SYBR Green qPCR Master Mix (Qiagen) containing $30 \mathrm{pg} / \mathrm{ml}$ of each primer with the following sequence (Morgan et al. 2017) MMP9 forward CACTGTAACTGGGGGCAACT, reverse CACTTCTTGTCAGCGTCGAA. And MMP2 forward: 5'-GAGAAAAGCGCAGCGGAGTGACG-3' reverse: 5'TTCCCCCGCAAGCCCAAGTG-3'. The cDNA was amplified by 40 cycles of 
denaturation at $95^{\circ} \mathrm{C}$ for $45 \mathrm{~s}$, annealing at $57^{\circ} \mathrm{C}$ for $45 \mathrm{~s}$ for MMP9 and $60{ }^{\circ} \mathrm{C}$ for $45 \mathrm{~s}$ for MMP2 and extension at $72^{\circ} \mathrm{C}$ for $45 \mathrm{~s}$. The size of all amplicons was confirmed by 2\% agarose gel electrophoresis stained with SYBR Safe DNA gel stain (Invitrogen). The GAPDH gene was amplified in the same reaction to serve as the reference gene. Each measurement was repeated 3 times, and the values were used to calculate the gene/GAPDH ratio, with a value of 1.0 used as the control (calibrator). The normalized expression ratio was calculated using the method described by Livak and Schmittgen (2001).

\subsection{Gelatin zymography}

Gelatin-zymography was performed according to the standard protocol reported by (Qiu et al. 2009). Liver samples were centrifuged at 6000xg for $30 \mathrm{~min}$. Then samples were mixed with an equal volume of $2 \times$ non reducing sample buffer $(1.5 \%$ SDS, 15 $\%$ glycerol, $0.025 \%$ bromphenol blue), and $50 \mu \mathrm{g}$ was loaded per well. MMP2 and MMP9 were analyzed on gelatin containing gels ( $10 \%$ polyacrylamide gel containing $0.1 \%$ gelatin). Gels were electrophoresed at $100 \mathrm{~V}$ in $1 \times$ running buffer. To remove SDS the gels were washed twice for $15 \mathrm{~min}$ in $2.5 \%(\mathrm{v} / \mathrm{v})$ Triton $\mathrm{X}-100$ and then immersed in incubation buffer $(50 \mathrm{mM}$ Tris- $\mathrm{HCl}, \mathrm{pH} 7.8,10 \mathrm{mM} \mathrm{CaCl}, 10 \mathrm{mM}$ NaN3) for $20 \mathrm{~h}, 37{ }^{\circ} \mathrm{C}$. Gels were stained with $0.25 \%$ Coomassie Brilliant Blue R. Destaining was performed with methanol-acetic acid-water (45:10:45 v/v/v). Quantification of the proteinase activities, which were expressed as arbitrary units per mg protein on the basis of size of the lysed area and intensity was performed using Image $\mathrm{J}$ software. The relative band intensity was calculated as a ratio to control.

\subsection{Statistical analysis}

The different analytical determinations in the biological samples were carried out in duplicate and results are expressed as the mean $\pm \mathrm{SD}$. Data for multiple variable 
comparisons were analyzed by one-way analysis of variance (ANOVA) test to analyze the significant differences (P 0.05) between groups using SPSS version 16 package for Windows.

\section{Results}

\subsection{Serum biochemistry}

The current results revealed that group II treated with TAA showed a significant elevation in liver induces including ALT, AST and ALP enzymes activity compared to control suggesting that the modeling was successful for induction of hepatic toxicity. The animals of group IV and V were administered QR or EA respectively showed significant reduction in biomarker enzymes levels as compared to group II and the percentage protection offered by the QR against the changes in AST, ALT and ALP were 12.9, 34.55 and $16.9 \%$ respectively, while the percentage of protection produced by EA (group V) was 23.89, 37.7 and $24.9 \%$ respectively (Table 1).

\subsection{Oxidative stress parameters}

From the current results reported in figure (1), it was obvious that, MDA the main indicative marker for lipid peroxidation (LPO) showed a significant elevation in group II intoxicated with TAA compared to control. Supplementation of QR to group IV and EA to group $\mathrm{V}$ caused significant reduction in the elevated MDA by $34.8 \%$ and $54.65 \%$ respectively. Under normal condition, the over production of ROS were neutralized by the antioxidant defense mechanisms which included both enzymatic and non enzymatic antioxidants that can be detected through the level of TAC. In the obtained results TAC was significantly reduced in group II intoxicated with TAA compared to control. Administration of either QR or EA to groups (VI and V) significantly elevated the TAC by $87.59 \%$ for QR and $91.98 \%$ for EA. GPX is a potent enzymatic antioxidant that scavenge harmful ROS, bringing the first line of 
defense against free radicals. In the current study, the administration of TAA to group II led to a significant reduction in GPX enzyme activity compared to control. Administration of QR or EA caused a significant increase in GPX enzyme activity by $43.47 \%$ and $99.13 \%$ respectively (figure 1 ).

\subsection{Matrix metalloproteinase 9 and 2 expression level}

Liver fibrosis is the common pathological foundation for several chronic hepatic diseases. To investigate the antifibrotic effects of both QR and EA on TAA induced liver fibrosis, the expression of MMP9 and MMP2 novel fibrotic and inflammatory markers were evaluated. According to results detected in figure (2) MMP9 and MMP2 appeared to over expressed by more than 4 folds in group II compared to control. Administration of QR to group IV induced significant down expression for both MMP9 and MMP2 by $34.88 \%$ and $35.89 \%$ compared to group II. In same line administration of EA to group V significantly reduced the expression level for MMP9 by $58.13 \%$ and $44.10 \%$ respectively compared with group II (figure 2 ).

\subsection{Zymography}

In pathological processes like liver fibrosis, the regulation of proteinase activity is disturbed. Densitometric analysis of gelatin-zymographic gel was done to semiquantify the percentage of matrix metalloproteinase (MMPs) activity. Density of the clear zone developed in the gelatin-zymographic gel by MMP2 and MMP9 was

calculated using Image $\mathrm{J}$ software. According to obtained data the administration of TAA induced significant elevation in lytic zone induced by both MMP9 and MMP2 compared to control. Decrease in density of the clear zones by either QR (group IV) or EA (group V) indicates the reduction in enzyme activity for both MMP9 and MMP2 (Figure 3). Administration of either QR or EA significantly reduced the gelatinase activity of MMP9 in liver tissue by $36.69 \%$ for QR and $42.44 \%$ for EA. In 
the same sequence the density of MMP2 band was significantly reduced in both QR and EA treated groups by $54.08 \%$ and $59.12 \%$ respectively.

\section{Discussion}

The present study evaluates the influence of QR or EA as dilatory supplementations on liver injury induced by TAA administration. Liver plays the main role in metabolism of different nutrients; in addition, it shares in clearance of waste products (Saleem et al. 2010). TAA considered as a selective hepatotoxin, used experimentally to induce hepatic failure (Zargar et al. 2017). The result of TAA metabolism is highly reactive compound (thioacetamide- $\mathrm{S}$ dioxide); it binds to the tissue macromolecules inducing sever hepatic injuries (Reddy et al. 2004). The current results revealed that injection of TAA (300 mg/kg BW) to adult male rats in the last $48 \mathrm{hr}$ of experimental period (45days) induces marked hepatic damage characterized by significant elevation liver function tests (AST, ALT and ALP) and hepatic MDA content as well as diminution of TAC and GPX enzyme activity. Those findings are consistent with Talluri et al (2016) and Miguel et al (2017) who reported that TAA induced hepatic toxicity and oxidative damage in rats. The liver enzymes are the most frequently diagnostic markers for liver cell damage and necrosis (Thapa and Walia 2007). Reduction in the activities of these hepatic enzymes, following QR or EA treatment (table 1) indicated the hepatoprotective potential of those flavonoids on the liver function (Taslidere et al. 2016; Afifia et al. 2016; Amin and Arbid 2017). Free radicals are continuously produced in the body, which may result into cell damage. Measurement of MDA level is mostly used to monitor LPO and indirectly, oxidative stress (Beltowski et al. 2000). Defensive responses of organisms to oxidative stress include the utilization of endogenous antioxidant enzyme systems, lipid soluble and water soluble antioxidant molecules and phytochemicals which can be detected 
through measurement of total antioxidant capacity (TAC). The antioxidant enzymes such as SOD, CAT and GPX are the main enzymes that act as defenses against oxidative damage. GPX is responsible for the catalytic decomposition of $\mathrm{H}_{2} \mathrm{O}_{2}$ to molecular oxygen and water (Khalaf et al.2017). According to the findings obtained, MDA level was significantly higher in group II compared to the control. In the same sequence there are significant reduction in both TAC and GPX enzyme activity (Figure 1). TAA administration induced severs oxidative damage in the rat liver was reported previously by Zargar et al (2017) and Miguel et al (2017). The significant reduction in the level of MDA and elevation of antioxidant status of tissue represented in significant elevation for TAC and GPX activity in liver after QR or EA treatments may be as a result of its antioxidant and free radical scavenging ability (Taslidere et al. 2016; Afifia et al.2016; Amin and Arbid 2017; Ansar et al. 2016). QR, a natural flavonoid considered as a potent antioxidant and activator for SOD and catalase enzyme activity (Hernández-Ortega et al. 2012). The antioxidant capacity of QR is attributed to its specific molecular structure, in which the oxygen active group, phenolic hydroxyls and 2,3-unsaturated double bond give QR strong antioxidant ability not only from accepting oxygen free radicals, but also by forming metal chelation compounds (Cui et al. 2014). QR also may be involved in the indirect induction of detoxifying genes decreasing the toxicity of xenobiotics by regulating gene expression or the activity of the cytochrome P450 enzymes (Polat et al. 2006) which promote detoxification of TAA. In the same sequence the antioxidant properties of EA might be attributed to its potent scavenging action on super oxide anion and hydroxyl anion (Galano et al. 2014). Because of its low solubility in water, EA was proposed as a lipophilic antioxidant and as a peroxyl radical scavenger. The antioxidant effect of EA may be involving dual actions: direct action on free radical 
scavenging and indirect action through the induction of antioxidant enzymes (Maher et al. 2016). Also EA increased the vitamin E level production especially in liver tissue (Özkaya et al. 2010) which is main natural antioxidant. EA has been known as good chelators agent which responsible for the protective action against mitochondrial damage. Thus, metal chelation is another way for EA to exert its protection against oxidative stress (Galano et al. 2014). Inflammation and oxidative stress may trigger a pathological condition by depositing extracellular matrix (ECM) inducing liver fibrosis (Rockey 2008) which may be leading to hepatic cirrhosis and hepatocellular carcinoma. In addition, there are no available drugs that can prevent or cure liver fibrosis in an optimum way (Bataller and Brenner 2005); therefore, the development of approaches to prevent hepatic fibrosis is a hot topic for recent researches (Algandaby et al. 2017). Antioxidants, particularly those of plant origin, have emerged as potent antifibrotic agents (Algandaby et al. 2017; Bona et al. 2012). To identify the antifibortic ability of QR and EA against liver fibrosis induced by TAA, the expression levels of some fibrosis related genes (MMP9 and MMP2) were evaluated. The obtained results showed that TAA successfully induced significant elevation of MMP9 and MMP2 expression level as markers for beginning the process of fibrosis (fibure 3 and 4). MMPs play a central role in ECM remodeling and are involved in a variety of pathogenic processes, such as inflammation and fibrosis (Kurzepa et al. 2014). The clinical relevance of these MMPs, in particular MMP2 and MMP9, has been associated with fibrosis in chronic liver disease (Duarte et al. 2015). TAA-induced liver fibrosis is caused by free radical-mediated LPO (Chen et al. 2015). Fatty acid accumulation due to TAA toxicity (Lin et al. 2017) also leads to the induction of ROS formation, which again hastens the hepatic injury and fibrosis (Algandaby et al. 2017; Algandaby 2016). ROS generation, mitochondrial 
dysfunction, and antioxidant insufficiency have been reported to advance the development of liver cirrhosis (Chen et al. 2015; Foo et al. 2011). Thus, oxidative stress also triggers production of inflammatory cytokines, causes inflammatory and fibrogenic responses, and is recognized as being of major importance in the progression of this disease. The current results showed that TAA induces proinflammatory responses, as evidenced by increased ROS production and matrix degrading enzyme activation (MMP 9 and MMP 2) which comes on sequence with result reported by Algandaby (2016) and Abdelghany et al. (2016). QR and EA supplementation possess therapeutic effects on hepatic fibrosis induced by TAA in rats through down-regulation of both MMP9 and MMP2 expression (figure 3, 4). The antifibrotic effect of EA was reported by several studies (Arafat et al. 2016; Devipriya et al. 2007). EA might have attenuated the collagen deposition and MMPs expression at least in part, by its antioxidant effects. EA had potent effect on CYP 450, in the sense that this product restores the liver cytochrome P450 enzymes could prevent LPO and helping in regeneration of hepatocytes (Girish et al. 2009). In addition, EA inhibits cytokine-induced activation of MAP kinases (Masamune et al. 2005), which might have indirectly decreased the expression of MMPs (Devipriya et al. 2007). In the same sequence this study showed a reduction in the expression of MMP2 and MMP9 after treatment with QR and this result is consistent with that obtained by Bona et al. (2012). QR has previously been reported to be antifibrotic in liver (Wan et al. 2014; Marcolin et al. 2012). QR down-regulate the expression of TGF $\beta 1$ stimulated fibronectin and collagen Ia, and MMP 2 and MMP 9 in dose dependant manner (Yoon et al. 2012). The antifibrotic effect for both QR and EA may be due to its interaction with zinc at the active site of MMP9 and MMP2 leading to its inactivation and thus relief fibrosis (Ahire et al. 2013). According to current results 
EA exert more anti-fibortic and antioxidant capacity than QR in most measured parameters. Those may be attributed to quercetin's low hydrophilicity results in minimal absorption in the gastrointestinal tract (Fearn et al. 2005). Some recent studies have shown that EA was found to be better than QR for chemoprevention (Özkaya et al. 2010). In addition, EA could be conjugated or metabolized by bacteria in the gut to produce urolithins. These microbial metabolites are more bioavailable than EA itself. So, these metabolites could be also responsible for the biological activity of EA (Gonzalez-Sarrias et al. 2010).

In summary, the data obtained suggest that attenuation of liver function tests, fibrotic related genes and alterations in redox status of hepatic tissue contribute to the beneficial effects of QR and EA in rats with TAA induced hepatic toxicity. Therefore, the results of this study indicate that QR and EA should be considered a candidate for the treatment and prevention of hepatotoxicity.

This work is original and has not been published elsewhere, nor is it currently under consideration for publication elsewhere.

\section{Competing interests}

"The authors declare that they have no competing interests to disclose."

\section{Authors' contributions}

Prof Dr. Nehal Afifi participated in the study design; Dr. Marwa Ibrahim and Dr. Mona Galal performed the molecular genetics parameters and evaluated the biochemical parameters. All authors read and approved the final manuscript. 


\section{References}

Abdelghany T. M. M., Abdelsalam R. A., Attia A. S and Elsayed M. E. 2016. Ramipril could attenuate thioacetamide-induced liver fibrosis in rats. The FASEB Journal.30(1). DOI: 10.1096/fj.1530-6860.

Afifia N. A., Ramadana A., El-Erakyb W., Salamab A. A., El-Fadalyb A. and Hassan A. 2016. Quercetin protects against thioacetamide induced hepatotoxicity in rats through decreased oxidative stress biomarkers, the inflammatory cytokines; (TNF- $\alpha),(\mathrm{NF}-\kappa \mathrm{B})$ and DNA fragmentation. Der Pharma Chemica.8(9):48-55.

Ahire V.R., Mishra K.P. 2016. Ellagic Acid Radiosensitizes Tumor Cells by Evoking Apoptotic Pathway. Journal of Radiation \& Cancer Research 7(3): 71-78. DOI: 10.4103/0973-0168.197973.

Algandaby M. M. 2016. Antifibrotic effects of crocin on thioacetamideinduced liver fibrosis in mice. Saudi Journal of Biological Sciences. doi.org/10.1016/j.sjbs.2016.10.007.

Algandaby M.M., Breikaa R.M., Eid B.G., Neamatallah T.A., Abdel-Naim A.B., Ashour O.M . 2017. Icariin protects against thioacetamide-induced liver fibrosis in rats: Implication of anti-angiogenic and anti-autophagic properties. Pharmacol Rep. Feb 24; 69(4):616-624. doi: 10.1016/j.pharep.2017.02.016.

Amin M. M., Arbid M. S. 2017. Estimation of ellagic acid and/or repaglinide effects on insulin signaling, oxidative stress, and inflammatory mediators of liver, pancreas, adipose tissue, and brain in insulin resistant/type 2 diabetic rats. Applied Physiology, Nutrition, and Metabolism, 42(2): 181-192. doi: 10.1139/apnm-2016-0429. Epub 2016 
Ansar S., Siddiqi N. J., Zargar S., Ganaie M. A and Abudawood M. 2016. Hepatoprotective effect of Quercetin supplementation against Acrylamide induced DNA damage in wistar rats. BMC Complementary and Alternative Medicine 16:327. https://doi.org/10.1186/s12906-016-1322-7.

Arafat S. Y., Nayeem M., Jahan S., Karim Z., Reza H. M., Hossain M. H.et al. 2016. Ellagic acid rich Momordica charantia fruit pulp supplementation prevented oxidative stress, fibrosis and inflammation in liver of alloxan induced diabetic rats. Orient Pharm Exp Med 16:267-278. DOI 10.1007/s13596-016-0242-x.

Bataller R., Brenner D.A. 2005. Liver fibrosis. J Clin Invest 115:209-218. DOI: $10.1172 / \mathrm{JCI} 24282$.

Beltowski J., Wójcicka G., Górny D., Marciniak A.2000. The effect of dietaryinduced obesity on lipid peroxidation, antioxidant enzymes and total plasma antioxidant capacity. J Physiol Pharmacol. 51:883-96.

Bona S., Filippin L. I., Naso F. D., David C. , Valiatti B., Schaun M. I.2012. Effect of Antioxidant Treatment on Fibrogenesis in Rats with Carbon Tetrachloride-Induced $\quad$ Cirrhosis. ISRN Gastroenterology. doi.org/10.5402/2012/762920.

Bradford M. M. A. 1976. Rapid and sensitive method for the quantitation of microgram quantities of protein utilizing the principle of protein-dye binding. Anal. Biochem. 72, 248-254. 
Buniatian G.H.2003. Stages of activation of hepatic stellate cells: effects of ellagic acid, an inhibiter of liver fibrosis, on their differentiation in culture. Cell Prolif. 36(6):307-19. DOI: 10.1046/j.1365-2184.2003.00287.x

Bursal E., Köksal E., Gülçin İ., Bilsel G and Gören A.C. 2013. Antioxidant activity and polyphenol content of cherry stem (Cerasus avium L.) determined by LC-MS/MS. Food Research International 51(1): 66-74. DOI 10.1016/j.foodres.2012.11.022

Cai X., Fang Z., Dou J., Yu A and Zhai G. 2013. Bioavailability of quercetin: problems and promises. Current Medicinal Chemistry 20(20): 2572-2582. DOI : $10.2174 / 09298673113209990120$

Chen X., Zhang Y., Yang L., Zu Y., Lu Q. 2015. Effects of rosmarinic acid on liver and kidney antioxidant enzymes, lipid peroxidation and tissue ultrastructure in aging mice. Food Funct. 6, 927-731. doi: 10.1039/c4fo01051e.

Choi Y.J., Kang J.S., Park J.H.Y., Lee Y., Choi J.S and Kang Y.H.2003. Polyphenolic flavonoids differ in their antiapoptotic efficacy in hydrogen peroxide-treated human vascular endothelial cells. The Journal of Nutrition 133(4): 985-991.

Cichoż-Lach H and Michalak A. 2014. Oxidative stress as a crucial factor in liver diseases. WJG 20(25): 8082. doi: $10.3748 /$ wjg.v20.i25.8082.

Cui Y., Han Y., Yang X., Sun Y and Zhao Y. 2014. Protective Effects of Quercetin and Quercetin-5',8-Disulfonate against Carbon TetrachlorideCaused Oxidative Liver Injury in Mice. Molecules. 19. 291-305. doi: 10.3390/molecules 19010291 
Deng X. H., Hang X and Li W.2000. Measurement of GSH-Px activity in serum by modified DTNB method. Chong Qing Med. J., 29: 445.

Devipriya N., Sudheer A.R., Srinivasan M., Menon V.P. 2007. Effect of Ellagic Acid, a Plant Polyphenol, on Fibrotic Markers (MMPs and TIMPs) during Alcohol-Induced Hepatotoxicity. Toxicol Mech Methods.17(6):349-56. doi: $10.1080 / 15376510601077003$.

Duarte S., Baber J., Fujii T., Coito A. J. 2015. Matrix metalloproteinases in liver injury, repair and fibrosis. Matrix Biology Volumes 44-46, May-July, Pages 147-156. doi: 10.1016/j.matbio.2015.01.004.

El-Nekeety A. A., Abdel-Azeim S. H., Hassan A. M., Hassan N.S., Aly S. E., Abdel-Wahhab M. A. 2014. Quercetin inhibits the cytotoxicity and oxidative stress in liver of rats fed aflatoxin-contaminated diet Toxicology Reports. 1:319-29. doi: 10.1016/j.toxrep.2014.05.014.

El-Shitany N.A., El-Bastawissy E.A., El-desoky K. 2014. Ellagic acid protects against carrageenan-induced acute inflammation through inhibition of nuclear factor kappa B, inducible cyclooxygenase and proinflammatory cytokines and enhancement of interleukin-10 via an antioxidant mechanism. Int Immunopharmacol. Apr;19(2):290-9. doi: 10.1016/j.intimp.2014.02.004.

Fearn R. A., Hirst B. H. 2005. Predicting oral drug absorption and hepatobiliary clearance: Human intestinal and hepatic in vitro cell Models. Environ. Toxicol. Phar. 21, 168-178. DOI: 10.1016/j.etap.2005.06.002

Foo N.P., Lin S.H., Lee Y.H., Wu M.J., Wang Y.J. 2011. a-Lipoic acid inhibits liver fibrosis through the attenuation of ROS-triggered signaling in 
hepatic stellate cells activated by PDGF and TGF-b. Toxicology. 2011 Mar 28;282(1-2):39-46. doi: 10.1016/j.tox.2011.01.009

Galano A., Marquez M. F., and Perez-Gonzalez A. 2014. Ellagic Acid: An Unusually Versatile Protector against Oxidative Stress. Chem. Res. Toxicol. 27, 904-918. doi: $10.1021 / \mathrm{tx} 500065 \mathrm{y}$.

García-Niño W.R and Zazueta C. 2015. Ellagic acid: Pharmacological activities and molecular mechanisms involved in liver protection. Pharmacological Research 97: 84-103. doi: 10.1016/j.phrs.2015.04.008.

Girish C., Koner B.C., Jayanthi S., Rao R. K., Rajesh B., Pradhan S.C.2009. Hepatoprotective activity of picroliv, curcumin and ellagic acid compared to silymarin on paracetamol induced liver toxicity in mice. Fundam Clin Pharmacol. Dec;23(6):735-45. doi: 10.1111/j.1472-8206.2009.

Gonzalez-Sarrias A., Larrosa M., Toms-Barberan F. A., Dolara P., and Espın J. C. 2010.NF- $\kappa$ B-dependent anti-inflammatory activity of urolithins, gut microbiota ellagic acid-derived metabolites, in human colonic fibroblasts. British Journal of Nutrition, vol. 104, no. 4, pp. 503-512. doi: $10.1017 / \mathrm{S} 0007114510000826$.

Guide for the Care and Use of Laboratory Animals (Eighth Edition, 2011, published by The National Academies Press, 2101 Constitution Ave. NW, Washington, DC 20055, USA).

Hernández-Ortega ～L.D., Alcántar-Díaz B.E., Ruiz-Corro ～L.A., SandovalRodriguez A., Bueno-Topete M., Armendariz-Borunda J. et al. 2012. Quercetin improves hepatic fibrosis reducing hepatic stellate cells and regulating pro-fibrogenic/anti-fibrogenic molecules balance. J Gastroenterol Hepatol. Dec;27(12):1865-72. doi: 10.1111/j.1440-1746.2012.07262.x. 
Khalaf A.A., Zaki A.R., Galal M.K., Ogaly H.A., Ibrahim M.A., Hassan A. 2017. The potential protective effect of $\alpha$ lipoic acid against nanocopper particle-induced hepatotoxicity in male rats. Hum Exp Toxicol. Sep;36(9):881-891. doi: 10.1177/0960327116674526

Kurzepa J., Mądro A., Czechowska G., Kurzepa J., Celiński K., Kazmierak Wet al. 2014. Role of MMP-2 and MMP-9 and their natural inhibitors in liver fibrosis, chronic pancreatitis and non-specific inflammatory bowel diseases. Hepatobiliary Pancreat Dis Int, Vol 13, No 6• December 15.

Lin Y., Lin H., Chen Y., Yang D., Li C., Chang Y. 2017. Hepatoprotective effects of naturally fermented noni juice against thioacetamide-induced liver fibrosis in rats Journal of the Chinese Medical Association 80. 212e221. DOI: http://dx.doi.org/10.1016/j.jcma.2016.10.014.

Livak K.J and Schmittgen T.D. 2001. Analysis of relative gene expression data using real-time quantitative PCR and the $2-\Delta \Delta$ CT method. Methods., 25 : 402-408. https://doi.org/10.1006/meth.2001.1262

Maher O. W., Raslan Y. A., Ahmed A. A .E ., Raafat E. M., Georgy G. S. 2016. The Ameliorative Effect of Ellagic Acid and Rosemarinic Acid against Cardio-nephrotoxicity Induced by Doxorubicin in Rats. International Journal of Scientific and Research Publications. 6 (2) February.

Marcolin E., San-Miguel B., Vallejo D., Tieppo J., Marroni N., GonzalezGallego J et al. 2012 . Quercetin Treatment Ameliorates Inflammation and 
Fibrosis in Mice with Nonalcoholic Steatohepatitis. J. Nutr. 142: 1821-1828. doi:10.3945/jn.112.165274.

Masamune A., Satoh M., Kikuta K., Suzuki N., Satoh K., Shimosegawa T. 2005. Ellagic acid blocks activation of pancreatic stellate cells. Biochem. Pharmacol. 70:869-878. DOI: 10.1016/j.bcp.2005.06.008.

Miguel F.M., Schemitt E.G., Colares J.R., Hartmann R.M, Morgan-Martins M.I., Marroni N.P. 2017. Action of vitamin E on experimental severe acute liver failure. Arq Gastroenterol .54 (2)Abr/Jun.125. doi:org/10.1590/S00042803.201700000-03.

Morgan A., Galal M.K., Ogaly H.A., Ibrahim M.A., Abd-Elsalam R.M., Noshy $\quad$ P. $2017 . \quad$ Tiron ameliorates oxidative stress and inflammation in titanium dioxidenanoparticles induced nephrotoxicity of male rats. Biomed Pharmacother. Sep;93:779-787. doi: 10.1016/j.biopha.2017.07.006.

Muriel P., Rivera-Espinoza Y. 2008. Beneficial drugs for liver diseases. J Appl Toxicol 28:93-103. DOI:10.1002/jat.1310

Ohkawa H., Ohishi N., Yagi K. 1979. Assay for lipid peroxides in animal tissues by thiobarbituric acid reaction. Anal. Biochem. 95, 351. DOI: $10.1016 / 0003-2697(79) 90738-3$

Özkaya A., Çelik A. S., Yüce A., Şahin Z .,Yilmaz O. 2010. The effects of ellagic acid on some biochemical parameters in the liver of rats against oxidative stress induced by aluminum. Kafkas Univ Vet Fak Derg 16 (2): 263268. DOI:10.9775/kvfd.2009.663.

Polat C., Tokyol C., Kahraman A., Sabuncuoglu B., Yilmaz S.2006. The effects of desferrioxamine and quercetin on hepatic ischemia-reperfusion 
induced renal disturbance. Prostaglandins Leukot Essent Fatty Acids. 74(6):379-83. DOI: 10.1016/j.plefa.2006.03.007.

Pradhan S. C., Girish C. 2006. Hepatoprotective herbal drug, silymarin from experimental pharmacology to clinical medicine. Indian J Med Res 124, November. pp 491-504.

Qiu Z., Dillen C., Hu J., Verbeke H., Struyf S., Van Damme J et al. 2009. Interleukin-17 regulates chemokine and gelatinase B expression in fibroblasts to recruit both neutrophils and monocytes. Immunobiology, vol. 214, no. 910, pp. 835-842DOI:http://dx.doi.org/10.1016/j.imbio.2009.06.007

Reddy P., Murthy C. R., Reddanna P.2004. Fulminant hepatic failure induced oxida-tive stress in nonsynaptic mitochondria of cerebral cortex in rats. Neurosci. Lett.368, 15-20. DOI: 10.1016/j.neulet.2004.06.046

Rockey D.C. 2008. Current and future anti-fibrotic therapies for chronic liver disease Clin Liver Dis 12:939-962, xi. doi: 10.1016/j.cld.2008.07.011 Salas-Villalobos T.B., Lozano-Sepúlveda S.A., Rincón-Sánchez A. R., GoveaSalas M., Rivas-Estilla A.M. 2017.Mechanisms involved in liver damage resolution after hepatitis $\mathrm{C}$ virus clearanceMedicina Universitaria.;19(75):100—107. https://doi.org/10.1016/j.rmu.2017.05.005

Saleem T. S. M., Chetty C. M., Ramkanth S., Rajan V., Kumar K. M., Gauthaman K. 2010. Hepatoprotective herbs-a review. Int. J. Res. Pharm. Sci. 1, 1-5.

Sanchez-Valle V., Cha' vez-Tapia N.C., Uribe M., Me'ndez-Sa' nchez N. 2012. Role of oxidative stress and molecular changes in liver fibrosis: a 
review. Curr. Med. Chem. 19, 4850-4860. DOI : $10.2174 / 092986712803341520$

Soong Y. Y and Barlow P.J.2004. Antioxidant activity and phenolic content of selected fruit seeds. Food Chemistry 88(3): 411-417. https://doi.org/10.1016/j.foodchem.2004.02.003

Talluri M. R., Tadi R. S., Battu G. R. 2016. Thioacetamide-induced acute liver toxicity in rats treated with Balanites roxburghii extract. The Journal of Acute Disease Volume 5, Issue 5, 1 September, Pages 413-418. https://doi.org/10.1016/j.joad.2016.08.009

Taslidere E., Dogan Z., Elbe H., Vardi N., Cetin A., Turkoz Y. 2016. Quercetin protection against ciprofloxacin induced liver damage in rats, Biotechnic \& $\quad$ Histochemistry, $\quad 91: 2, \quad 116-121$. https://doi.org/10.3109/10520295.2015.1085093

Thapa B., Walia A. 2007. Liver function tests and their interpretation. Indian J.Pediatr. 74, 663-671. doi: 10.1007/s12098-007-0118-7.

Tieppo J., Cuevas M.J., Vercelino R., Tuñón M.J, Marroni N .P, GonzálezGallego J. 2009. Quercetin administration ameliorates pulmonary complications of cirrhosis in rats, J. Nutr. 139.1339-1346.

Wan A. Y., Tang M. H., Chen X. C., Chen L. J., Wei Y. Q and Wang Y.S. 2014. Inhibitory effect of liposomal quercetin on acute hepatitis and hepatic fibrosis induced by concanavalin. Brazilian Journal of Medical and Biological Research. 47(8): 655-661. http://dx.doi.org/10.1590/1414-431X20143704 . 
Yogalakshmi B., Viswanathan P., Anuradha C. V. 2010. Investigation of antioxidant, anti-inflammatory and DNA-protective properties of eugenol in thioacetamide-induced liver injury in rats, Toxicology, 268(3):204-12. doi: 10.1016/j.tox.2009.

Yoon J. S., Chae M. K., Jang S.Y, Lee S Y,1 and Lee E.J. 2012. Antifibrotic Effects of Quercetin in Primary Orbital Fibroblasts and Orbital Fat Tissue Cultures of Graves' Orbitopathy Invest Ophthalmol Vis Sci.53:5921-5929. doi:10.1167/iovs.12-9646.

Zargar S., Wani T. A., Alamro A. A and Ganaie M. A. 2017. Amelioration of thioacetamide-induced liver toxicity in Wistar rats by rutin. International Journal of Immunopathology and Pharmacology 1-8. https://doi.org/10.1177/0394632017714175. 
Tables

Table (1) Protective influence of $Q R$ and EA on the liver function tests against TAA induced hepatotoxicity

\begin{tabular}{|l|l|l|l|l|l|}
\hline & Group I & Group II & Group III & Group IV & Group V \\
\hline ALT & $20.3 \pm 1.2^{\mathrm{a}}$ & $92.6 \pm 4.2^{\mathrm{b}}$ & $38.7 \pm 3.55^{\mathrm{c}}$ & $60.6 \pm 3.3^{\mathrm{d}}$ & $57.6 \pm 0.7^{\text {ed }}$ \\
\hline AST & $55.2 \pm 0.9^{\mathrm{a}}$ & $176.6 \pm 2.9^{\mathrm{b}}$ & $123.3 \pm 3.1^{\mathrm{c}}$ & $153.8 \pm 1.58^{\mathrm{d}}$ & $134.4 \pm 1.2^{\text {ce }}$ \\
$\mathrm{U} \backslash \mathrm{L}$ & & & & & \\
\hline ALP & $258 \pm 3.7^{\mathrm{a}}$ & $433.7 \pm 10.2^{\mathrm{b}}$ & $333.6 \pm 9.2^{\mathrm{ca}}$ & $363.45 \pm 4.2^{\mathrm{cdb}}$ & $325.65 \pm 5.9^{\text {eacd }}$ \\
$\mathrm{U} \backslash \mathrm{L}$ & & & & & \\
\hline
\end{tabular}

Data are presented as (Mean \pm S.D). S.D $=$ Standard deviation. Mean values with different superscript letters in the same row are significantly different at $(\mathrm{p} \leq 0.05)$. 
Figures

Figure (1) Protective influence of $Q R$ and EA on the antioxidant parameters against TAA induced hepatotoxicity. Data were expressed as means \pm S.D. Groups having different letters are significantly different from.

Figure 2. Protective influence of $Q R$ and EA on the expression level of MMP9 and MMP2 against TAA induced hepatotoxicity (A) Fold change of mRNA expression of MMP9 (B) Fold change of mRNA expression of MMP2 rat liver of different experimental groups using qPCR. Data are represented as mean $\pm \mathrm{SD}$. Different superscripts are significantly different. (C) The results obtained by real-time PCR analysis were confirmed by agarose gel electrophoresis analysis of the PCR product compared to GAPDH.

Figure (3) Protective influence of QR and EA on the protein expression level of MMP9 and MMP2 against TAA induced hepatotoxicity (A) Representive gelatin zymography to analyze the activities of MMP 9 and MMP2 in the liver tissue (1-5 represent the different experimental groups respectively ( 1 is group I---- and 5 is group IV) S: conditioned media). (B) Relative band density for MMP9 (C) Relative band density for MMP2. Data are represented as mean \pm SD. Different superscripts are significantly different. 


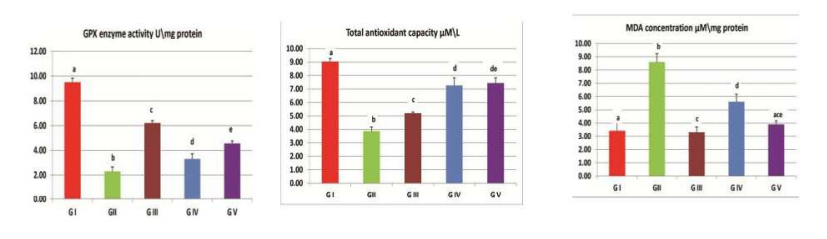

Figure (1) Protective influence of QR and EA on the antioxidant parameters against TAA induced hepatotoxicity. Data were expressed as means \pm S.D. Groups having different letters are significantly different from.

$210 \times 297 \mathrm{~mm}(300 \times 300 \mathrm{DPI})$ 


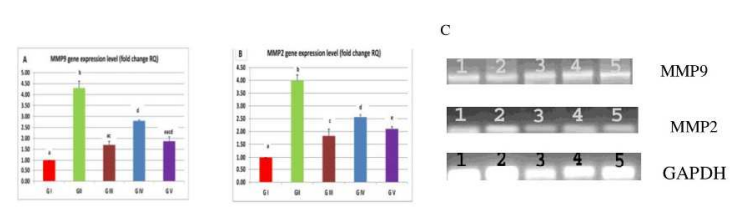

Figure 2. Protective influence of $Q R$ and $E A$ on the expression level of MMP9 and MMP2 against TAA induced hepatotoxicity (A) Fold change of mRNA expression of MMP9 (B) Fold change of mRNA expression of MMP2 rat liver of different experimental groups using qPCR. Data are represented as mean $\pm S D$. Different superscripts are significantly different. (C) The results obtained by real-time PCR analysis were confirmed by agarose gel electrophoresis analysis of the PCR product compared to GAPDH.

$$
210 \times 297 \mathrm{~mm}(300 \times 300 \mathrm{DPI})
$$




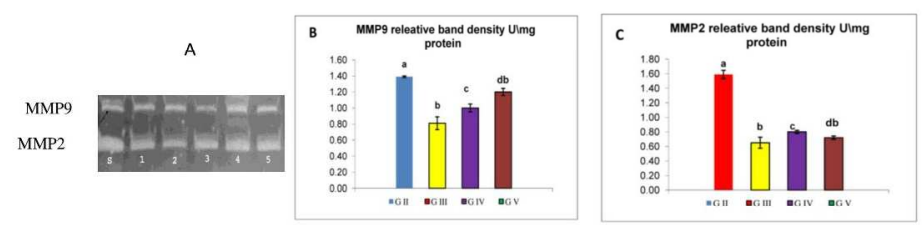

Figure (3) Protective influence of QR and EA on the protein expression level of MMP9 and MMP2 against TAA induced hepatotoxicity (A) Representive gelatin zymography to analyze the activities of MMP 9 and MMP2 in the liver tissue (1-5 represent the different experimental groups respectively ( 1 is group I---- and 5 is group IV) S: conditioned media). (B) Relative band density for MMP9 (C) Relative band density for MMP2. Data are represented as mean \pm SD. Different superscripts are significantly different.

$$
210 \times 297 \mathrm{~mm} \text { ( } 300 \times 300 \text { DPI) }
$$

